\title{
Effect of deformation temperature on bainitic transformation and microstructure of a medium carbon high strength bainite steel
}

\author{
Z. Wang, G. Xu*, M. Liu, G. Chen, H. Hu \\ The State Key Laboratory of Refractories and Metallurgy, Key Laboratory for Ferrous Metallurgy and Resources \\ Utilization of Ministry of Education, Wuhan University of Science and Technology,
} 947 Heping Ave, Wuhan 430081, P. R. China

Received 3 March 2020, received in revised form 1 August 2020, accepted 9 September 2020

\begin{abstract}
The effect of deformation temperature on bainitic transformation was investigated by dilatometry, microstructure, and X-ray diffraction analysis. The results indicate that deformation accelerates initial bainite transformation by increasing nucleation sites. There is a critical temperature to promote the amount of bainitic transformation. When the ausforming temperature decreases below the critical temperature $\left(525^{\circ} \mathrm{C}\right)$, the final amount of bainite is larger than that of non-deformation steel. In addition, the microstructures of all specimens consist of needle-like bainite, film-like retained austenite (RA), and blocky martensite, while the finer microstructure and shorter bainite are observed in deformed specimens.
\end{abstract}

Key words: bainitic transformation, ausforming temperature, retained austenite (RA), deformation

\section{Introduction}

The bainitic transformation has always been a hot topic since bainite steel was proposed in the late 1920s [1]. Low-temperature bainite exhibits a superior combination of high strength and good ductility. Still, its transformation usually takes a long time, which limits the practical application of high strength bainite steels. Researchers have tried to alleviate this defect and investigated multiple affecting factors related to bainite transformation.

Abundant papers on bainite steels have investigated the effects of austenitizing temperature, chemical component, and deformation on bainitic transition. For example, some researchers reported that larger austenite grains accelerate the transition in super bainite steels [2-4]. As for chemical composition, Reynolds et al. discussed the influences of different alloy elements on bainitic incomplete transformation and found that some Fe-C-X alloys present incomplete bainitic transformation [5]. The addition of Si can retard the formation of carbides, and $\mathrm{Ni}$ addition decreases the final amount of bainite, while chromium can increase bainite amount [6,7]. Molybdenum is reported to promote the phase transformation of bai- nite $[8,9]$. Garcia-Mateo et al. discussed the effects of $\mathrm{Cr}$, Mo, and $\mathrm{Nb}$ addition on bainite steels and provided optional design of bainite steel to shorten transformation time [10]. Besides, some papers also established the kinetic models of bainitic transformation with or without stress to give a better understanding of bainitic transformation [11, 12].

Besides the investigations above, ausforming technique as an alternative method to promote bainitic transformation has also been proposed in recent years [13-16]. It is reported that low-temperature ausforming is beneficial to bainite transformation [16]. Some studies pointed out that high temperature retards the transformation rate of bainite [17]. Hu et al. investigated the effect of deformation on bainitic transformation at $300^{\circ} \mathrm{C}$. They found that small strain promotes bainite transformation, while immense strain such as 0.5 is detrimental to bainite transformation [18]. Multi-step ausforming process can promote lowtemperature bainitic transformation and lessen big blocky retained austenite (RA), which is reported to be detrimental to tensile behavior $[19,20]$. Zhou et al. clarified when the strain exceeds the critical value, mechanical stabilization caused by deformation becomes serious, resulting in a smaller amount of bai-

*Corresponding author: tel.: +86-156-9718-0996; fax: +86-27-6886-2807; e-mail address: xuguang@wust.edu.cn 


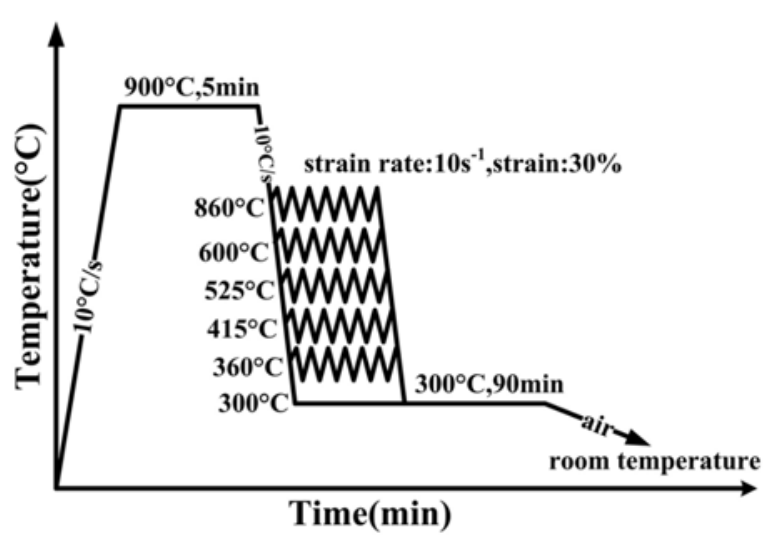

Fig. 1. Experimental procedure.

nite [21]. Freiwillig et al. investigated the effect of a 5-40\% strain of austenite on bainitic transformation and claimed that deformation shortens the incubation period of bainitic transformation [22]. Chen et al. designed different strain rates of ausforming and claimed that $30 \%$ deformation at various rates all increases the amount of bainite, and strain rates show a nonlinear relationship with the promotion effect [23].

So far, there are different opinions about the effect of ausforming on bainite steels. Some researchers believed that bainitic transformation is prompted by ausforming [15, 16], while some others claimed that ausforming retards bainitic transformation [17, 24, $25]$. It is reasonable to speculate that the different results may be attributed to the ausforming condition, especially ausforming temperature. Therefore, five different deformation temperatures were designed in the present study to investigate the effect of ausforming temperature on bainitic transformation.

\section{Experiments}

The chemical composition of the steel in this study is $\mathrm{Fe}-0.4 \mathrm{C}-1.5 \mathrm{Si}-2.2 \mathrm{Mn}-0.22 \mathrm{Mo}$ (wt.\%). The experimental steel was refined in a laboratory vacuum reduction furnace and cast into a $50 \mathrm{~kg}$ ingot followed by finally hot-rolling and air-cooling to ambient temperature. The samples were machined to cylindrical specimens with a diameter of $6.0 \mathrm{~mm}$ and a length of $15.0 \mathrm{~mm}$ for the thermal simulation experiments on a Gleeble-3500 thermal simulator. The experimental procedure is schematically illustrated in Fig. 1. The specimens were heated to $900{ }^{\circ} \mathrm{C}$ and austenized for $5 \mathrm{~min}$, and then cooled to $860,600,525,415$, and $360^{\circ} \mathrm{C}$ followed by deformation to a strain of $30 \%$ at a strain rate of $10 \mathrm{~s}^{-1}$. The compression process was controlled by an automatic control system, and the uniaxial compressive deformation was immedi-

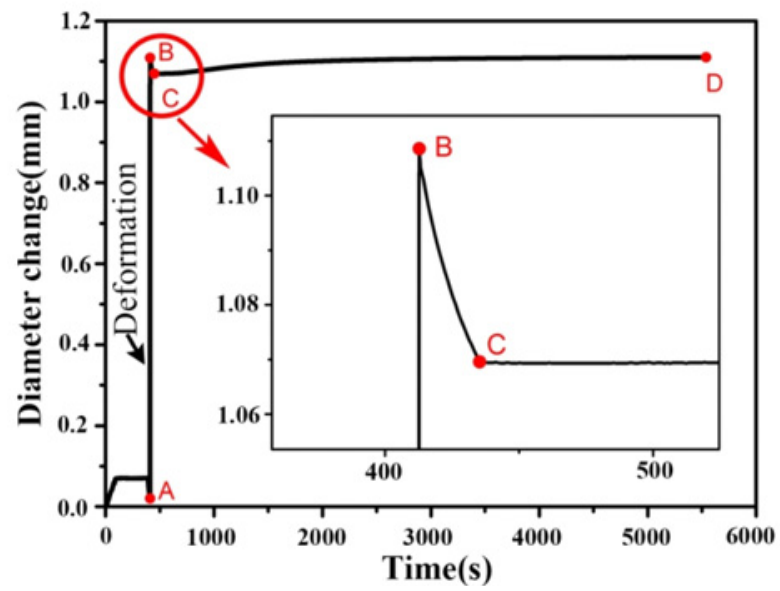

Fig. 2. Diameter change versus time of specimen deformed at $525^{\circ} \mathrm{C}$ and isothermal holding at $300^{\circ} \mathrm{C}$ for $90 \mathrm{~min}$.

ately imposed on the samples when the temperature reached the target temperatures $(860,600,525,415$, and $360^{\circ} \mathrm{C}$ ). After ausforming, the specimens were cooled to $300^{\circ} \mathrm{C}$ and held for $30 \mathrm{~min}$ for bainitic transformation. The non-deformed sample was also treated at $300^{\circ} \mathrm{C}$ for $30 \mathrm{~min}$ to be compared with deformed specimens. The bainite and martensite transformation starting temperatures were calculated to be 449 and $282^{\circ} \mathrm{C}$, respectively, using MUCG83 software developed by Bhadeshia at Cambridge University. The dilation data of all specimens during the whole heat treatment were recorded by a laser dilatometer. A Nova400Nano field emission scanning electron microscope (FE-SEM) and a JEM-2100F transmission electron microscope (TEM) were utilized to identify the microstructural characteristics of specimens.

\section{Results and discussion}

\subsection{Dilatation}

During the thermal simulation, the changes in specimens' diameter were recorded by a laser dilatometer. The diameter changes versus time are drawn in Fig. 2, where points A, B, and C represent the start of deformation, the end of deformation, and the beginning of bainitic transformation, respectively. The decreasing part of BC is caused by elastic recovery after unloading. The dilation change is caused by bainitic transformation and is usually used to represent transformation amounts of bainite [18]. Since the increase of dilation after point $\mathrm{C}$ is caused by bainitic transformation with holding at $300^{\circ} \mathrm{C}$ for $90 \mathrm{~min}$, the amount of bainite in different samples is comparable by dilation change in part CD during the whole process of isothermal transformation.

Since the temperature and the stress both influence the bainitic transformation $[1,11]$, two influence 


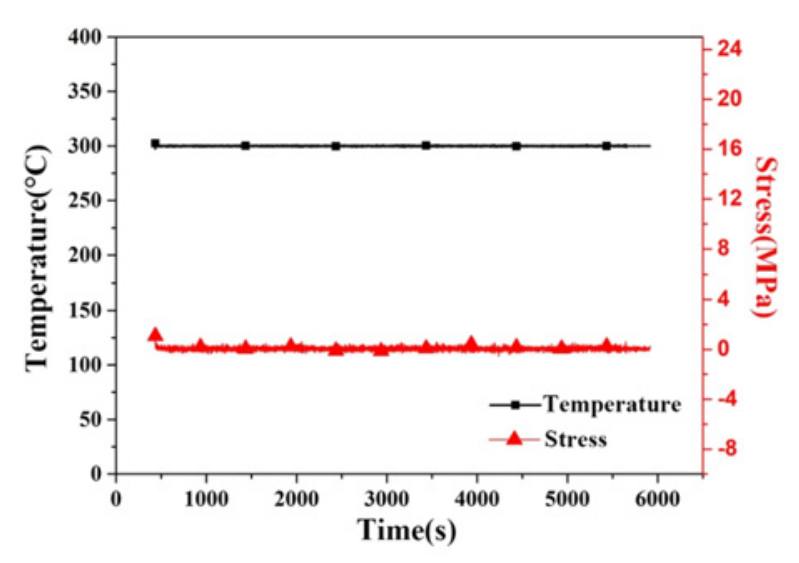

Fig. 3. Stress and temperature during the isothermal holding process.

factors were checked and shown in Fig. 3. Figure 3 represents the temperature-time and stress-time curves during the isothermal holding process at $300^{\circ} \mathrm{C}$ for $90 \mathrm{~min}$. It indicates that the stress applied to the specimens is below $2 \mathrm{MPa}$, and the temperature remains at $300{ }^{\circ} \mathrm{C}$, meaning that the effects of fluctuations of temperature and stress on the bainitic transformation can be ignored.

The dilation is related to the initial diameter of the specimen. The larger the diameter of the specimen is, the larger the dilation change is at the condition of the same transformation. To compare the bainitic transformation reasonably, dilatation amounts of different specimens were normalized by the formula $D_{\mathrm{i}}-D_{0} / d_{0}$ [23]. $D_{\mathrm{i}}$ is the momentary value of dilation during the whole bainitic transformation process, $D_{0}$ is the dilation value of point $\mathrm{C}$ in Fig. 2 corresponding to the onset of bainite transformation, and $d_{0}$ is the initial diameter at point C. Figure 4 a presents the normalized dilatation and transformation rate of samples compressed at different temperatures as the function of time. In comparison with the non-deformed sample, the initial transformation rates of deformed specimens are all accelerated. However, with the temperature increasing, decomposing austenite rates after deformation slow down, suggesting that higher ausforming temperature weakens the kinetics of bainite transformation. This is because deformation provides more nucleation sites to accelerate bainitic transformation [15]. But dynamic recovery may happen [22] during the deformation, and static recovery may occur in the following cooling stage at high temperature, leading to fewer nucleation sites and making the phase transformation slow down. The transformation rates for three deformation conditions are shown in Fig. 4b. In the later stage of bainite transformation, bainite transformation in deformed samples is hampered more obviously compared to non-deformed steel due to the
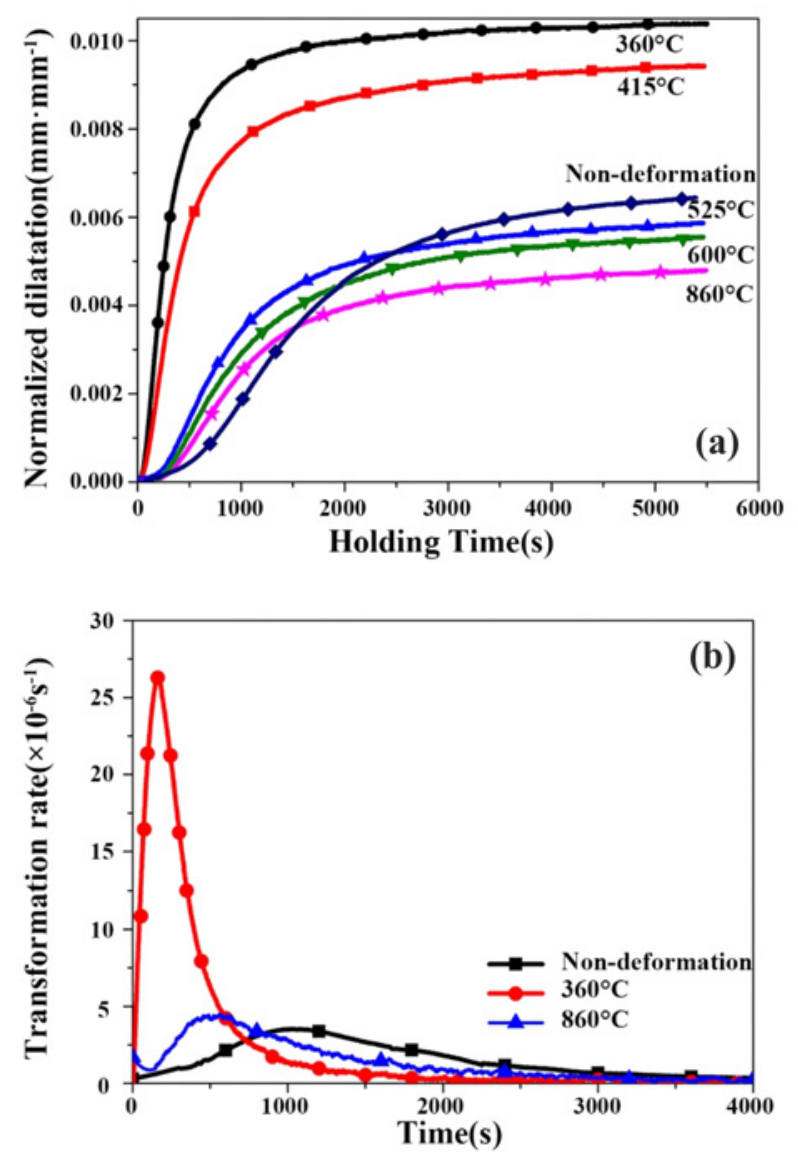

Fig. 4. (a) Normalized dilatation versus temperature and (b) transformation rates.

dislocation and defects induced by compression. Deformation at $360^{\circ} \mathrm{C}$ hampers bainite transformation more severely because of more defects in the specimen compared to deformation at $860{ }^{\circ} \mathrm{C}$.

In addition, the final dilatation versus temperature is depicted in Fig. 5. The bainite amount of specimens deformed at 360 and $415^{\circ} \mathrm{C}$ is larger than that of the non-deformed specimen. Therefore, low-temperature deformation accelerates not only the initial transformation rate but also increases the final bainite amount. However, dilatation goes down with the temperature going up. When the ausforming temperature is higher than $525^{\circ} \mathrm{C}$, the final amount of bainite is even smaller than that in the non-deformed specimen, indicating bainitic transformation is retarded even though the initial transformation is accelerated. In general, ausforming decreases the incubation period and accelerates initial bainite transformation due to more nucleation sites provided by deformation. Low-temperature deformation can promote the whole process of transition and increase the final amount of bainite. Though high-temperature compression speeds up the initial transformation, it retards the latter process of transition. Ausforming plays two opposite roles in 


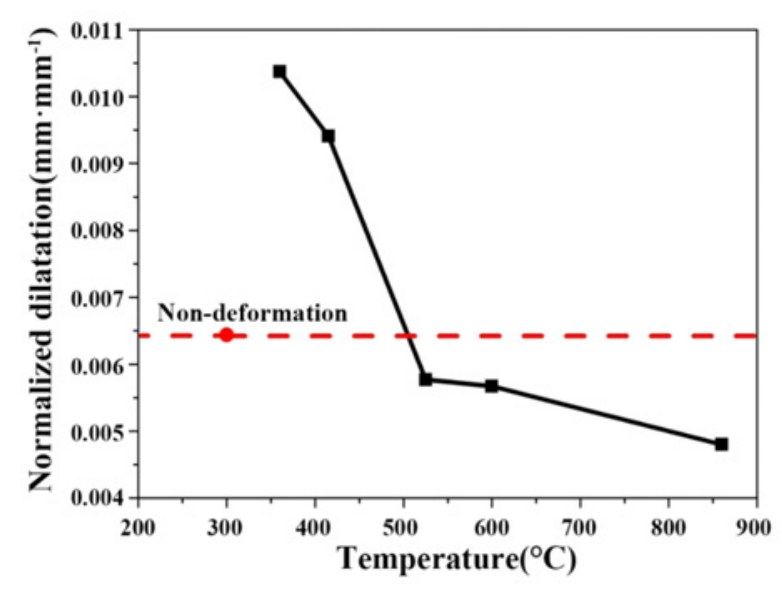

Fig. 5. Final dilatation versus temperature.

the latter stage of bainitic transformation [22]: positive effect on nucleation and negative effect on bainite growth. Considerable dislocations are induced during ausforming, which provides substantial nucleation sites for bainite transformation. On the other hand, sub-structures and accumulative debris restrain the growth of bainite. Lots of dislocations and substructures are introduced during low-temperature deformation, which significantly increases the nucleation sites for bainitic transformation and promotes the initial bainite transition. In the later stage of transformation, although sub-grains retard bainite growth, the final bainite transformation is still more extensive than that of the undeformed sample because of the apparent large initial amount of phase transformation. This is confirmed by the transformation rate in Fig. 4b. Also, compared with the non-deformed sample, the bainitic transformation is hindered in samples deformed at high temperatures because bainite growth is retarded by dislocations and deformation defects [22], resulting in smaller final bainite amount even though the initial transformation is accelerated.
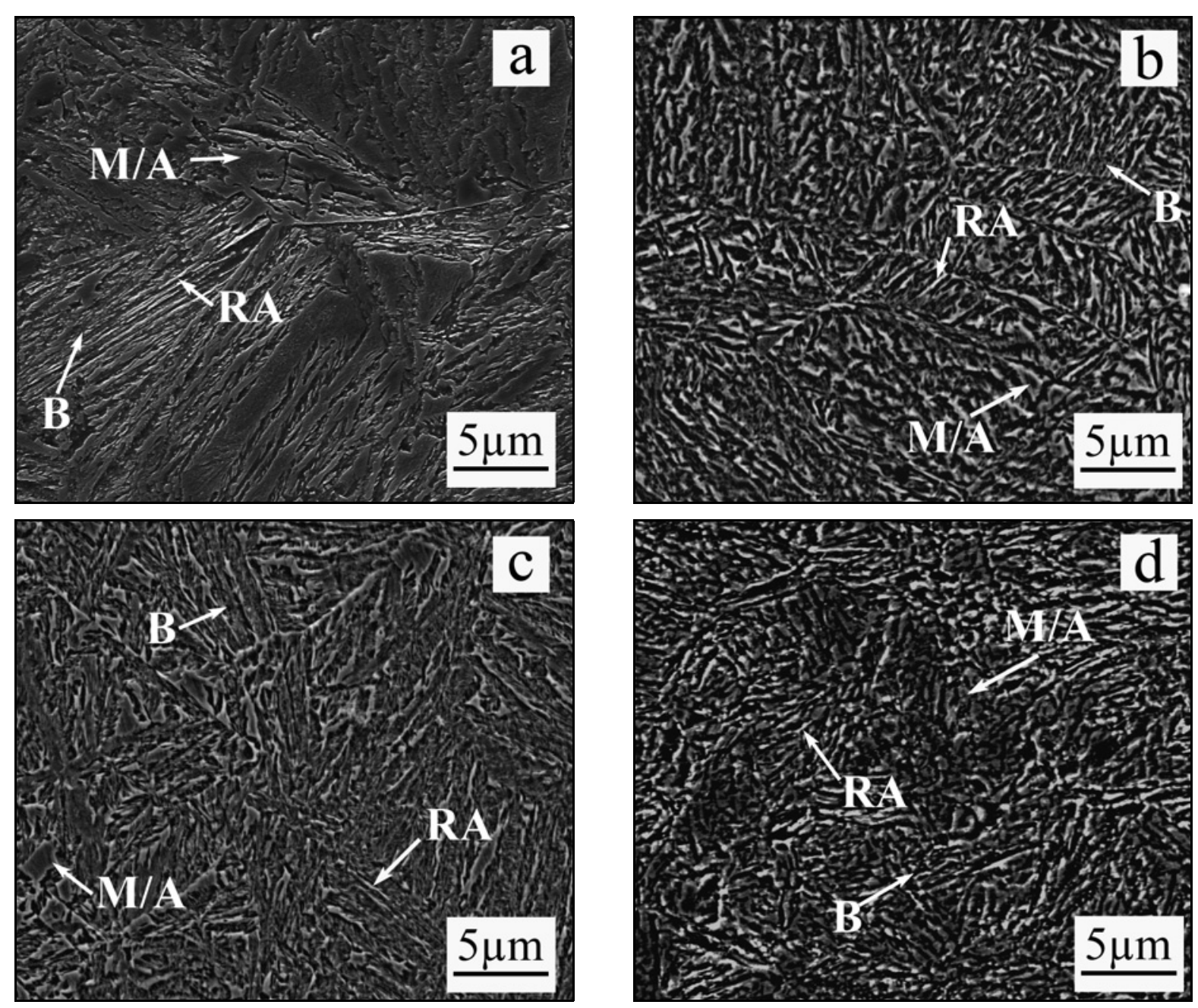

Fig. 6. Microstructure of specimens: (a) non-deformed, (b) deformed at $360^{\circ} \mathrm{C}$, (c) deformed at $600{ }^{\circ} \mathrm{C}$, and (d) deformed at $860^{\circ} \mathrm{C}$. 

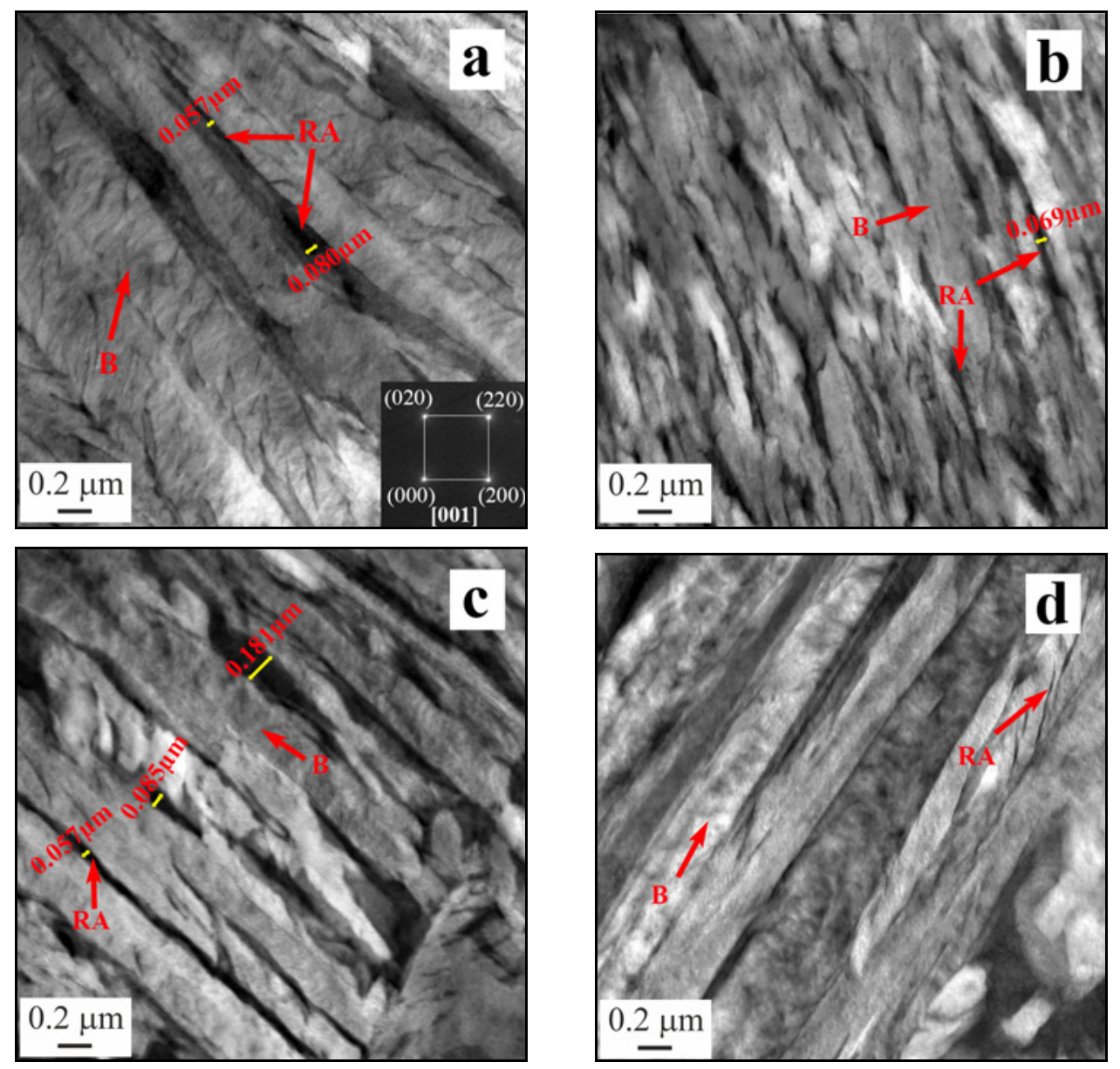

Fig. 7. TEM images of the filmy austenite between bainite sheaves: (a) non-deformed, (b) deformed at $360^{\circ} \mathrm{C},(\mathrm{c})$ deformed at $600{ }^{\circ} \mathrm{C}$, and (d) deformed at $860^{\circ} \mathrm{C}$.

Therefore, it is reasonable to infer that there is a critical ausforming temperature to facilitate bainitic transformation. Below the critical temperature, bainitic transformation is promoted compared with non-deformed specimens, while transformation is hindered when the temperature is higher than the critical temperature.

\subsection{Microstructure}

The processed specimens were ground with $\mathrm{SiC}$ papers, polished with a polishing machine, and etched with a $4 \%$ natal solution. FE-SEM at an acceleration voltage of $20 \mathrm{kV}$ was utilized to observe the microstructural characteristics of specimens. Martensite, bainite, and austenite coexist in both deformed and non-deformed specimens. During the isothermal process, austenite decomposes to bainite accompanied by the emission of carbon atoms [1]. Residual austenite transforms into martensite in the cooling process after isothermal holding at $300^{\circ} \mathrm{C}$. Some retained austenite (RA) is obtained when specimens are cooled to ambient temperature. In all specimens, bainite sheaves and blocky M/A are observed and pointed out by arrows in Fig. 6. Besides, compared to non-deformed specimens, finer and shorter bainite sheaves are detected in deformed specimens. The amount of bainite in specimens deformed at $360^{\circ} \mathrm{C}$ is much larger than that of non-deformed, while deformation at 600 and $860^{\circ} \mathrm{C}$ decreases the volume fraction of bainite. The microstructure results are consistent with dilatation results.

Figure 7 exhibits TEM micrographs of filmy retained austenite existing between bainite sheaves in the above specimens. The black areas between bainite sheaves are filmy RA, while the bright areas are bainite sheaves, which are pointed by arrows. The blocky area in the red circle is martensite/austenite island. Furthermore, Fig. 7a shows the selected area electron diffraction (SAED) pattern obtained from one of the dark regions with [001] zone, and the dark region can be indexed as the face-centered cubic austenite structure $(\gamma-\mathrm{Fe})$, which testified that the dark area in Fig. 7a is RA. It can be seen that the width of the majority of filmy RA is less than $0.1 \mu \mathrm{m}$, which is beneficial to the properties [19]. 


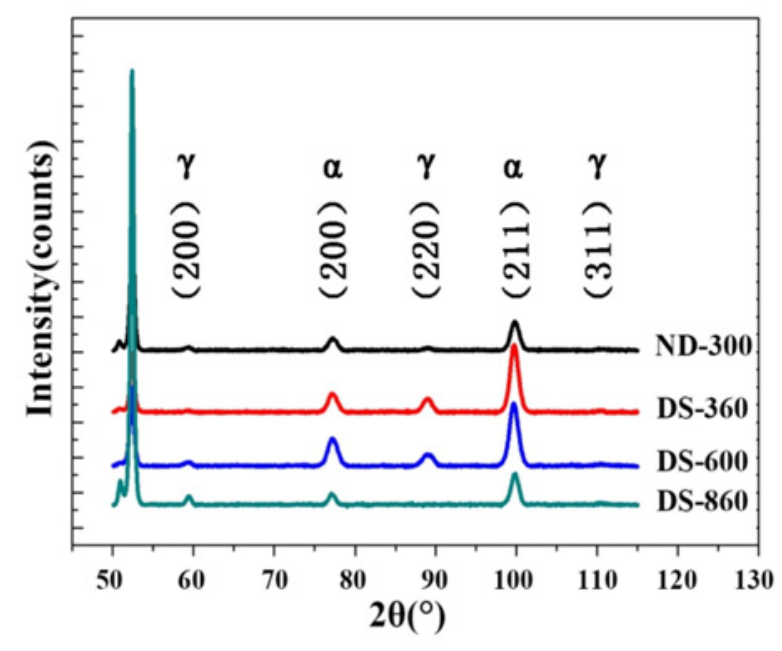

Fig. 8. Diffraction peaks of different specimens.

Table 1. Volume fractions of RA in different samples

\begin{tabular}{ll}
\hline Specimens & RA $(\%)$ \\
\hline ND-300 & 15.935 \\
DS-360 & 19.43 \\
DS-600 & 19.21 \\
DS-860 & 18.36 \\
\hline
\end{tabular}

\section{3. $X R D$ results}

To quantitatively measure the volume fraction of $\mathrm{RA}$ in different samples, an X'Pert diffractometer with Co $\mathrm{K} \alpha$ radiation operated at an acceleration voltage of $40 \mathrm{kV}$, current of $150 \mathrm{~mA}$, and step of $0.06^{\circ}$ was used for XRD analysis. Diffraction peaks of specimens are shown in Fig. 8. ND-300 refers to the specimen nondeformed and isothermally held at $300^{\circ} \mathrm{C}$. DS-360, DS-600, and DS-860 represent deformed specimens at 360,600 , and $860^{\circ} \mathrm{C}$, respectively.

Equation (1) was used to calculate the amount of RA based on the integrated intensities of the various diffraction peaks $[24,26]$ :

$$
V_{i}=\frac{1}{1+G\left(I_{\alpha} / I_{\gamma}\right)}
$$

where $V_{i}$ is the amount of austenite for each peak, $I_{\alpha}$ and $I_{\gamma}$ are the integrated intensities of the ferrite and austenite peaks, respectively, and $G$ is the constant for each peak. Table 1 shows the calculated results. It can be seen that the non-deformed specimen contains the smallest amount of RA of $15.935 \%$. Higher amounts of RA are retained in the ausformed steels. Moreover, the volume fraction of RA decreases from 19.43 to $18.36 \%$, with ausforming temperature increasing from 360 to $860^{\circ} \mathrm{C}$. The mechanical stability of austenite occurs in deformed samples. Mechanical stability retards martensite transformation, leading to less martensite and more amounts of RA in deformed specimens than that in non-deformed specimens. In addition, bainite transformation results in carbon-rich residual austenite and increases the chemical stability of untransformed austenite. The larger amount of bainite at low-temperature deformation causes higher chemical stability of residual austenite and more RA.

\section{Conclusions}

Five ausforming temperatures were designed to investigate the effects of deformation temperature on bainitic transformation. The effects of deformation temperature on bainitic transformation were enunciated. The following conclusions can be drawn:

(1) Initial bainite transformation is accelerated by deformation at all temperatures.

(2) There is a critical temperature to promote bainitic transformation. Below the critical temperature, bainite transformation is promoted, leading to more bainite. In contrast, beyond the critical temperature, bainitic transformation is retarded, resulting in a smaller bainite amount than that in non-deformed steel.

(3) The microstructures of all specimens consist of needle-like bainite, film-like RA, blocky martensite. Finer and shorter bainite plates are observed in deformed specimens.

\section{Acknowledgements}

The authors gratefully acknowledge the financial support from the National Natural Science Foundation of China (NSFC) (Nos. 51874216, 51704217), the Major Projects of Technology Innovation of Hubei Province (2017AAA116), and the Joint Key Project of Hebei Iron and Steel Group (No. HG2019313).

\section{References}

[1] H. K. D. H. Bhadeshia, J. W. Christian, Bainite in steels, Metall. Mater. Trans. A 21(1990) 767-797. doi:10.1007/BF02656561

[2] F. Hu, P. D. Hodgson, K. M. Wu, Acceleration of the super bainite transformation through a coarse austenite grain size, Mater. Lett. 122 (2014) 240-243. doi:10.1016/j.matlet.2014.02.051

[3] M. X. Zhou, G. Xu, L. Wang, H. J. Hu, Effect of undercooling and austenitic grain size on bainitic transformation in an Fe-C-Mn-Si superbainite steel, T. Indian I. Metals, 69 (2016) 693-698. $\underline{\text { doi: } 10.1007 / \mathrm{s} 12666-015-0541-9}$ 
[4] G. Xu, F. Liu, L. Wang, H. J. Hu, A new approach to quantitative analysis of bainitic transformation in a superbainite steel, Scr. Mater. 68 (2013) 833-836. doi:10.1016/i.scriptamat.2013.01.033

[5] W. T. Reynolds, S. K. Liu, F. Z. Li, S. Hartfield, H. I. Aaronson, An investigation of the generality of incomplete transformation to bainite in $\mathrm{Fe}-\mathrm{C}-\mathrm{X}$ alloys, Metall. Mater. Trans. A 21 (1990) 1479-1491. doi: $10.1007 / \mathrm{bf} 02672563$

[6] Z. S. Yao, G. Xu, H. J. Hu, Q. Yuan, J. Y, Tian, Effect of $\mathrm{Ni}$ and $\mathrm{Cr}$ addition on transformation and properties of low-carbon bainitic steels, T. Indian I. Metals 72 (2019) 1167-1174. doi:10.1007/s12666-019-01590-7

[7] S. K. Liu, J. Zhang, The influence of the Si and Mn concentrations on the kinetics of the bainite transformation in Fe-C-Si-Mn alloys, Metall. Mater. Trans. A 21 (1990) 1517-1525. doi:10.1007/bf02672566

[8] H. J. Hu, G. Xu, L. Wang, Z. L. Xue, Y. L. Zhang, G. $\mathrm{H}$. Liu, The effects of $\mathrm{Nb}$ and Mo addition on transformation and properties in low carbon bainitic steels, Mater. Des. 84 (2015) 95-99. doi:10.1007/bf02672566

[9] J. M. Reichert, M. Militzer, Quantifying the effect of $\mathrm{Nb}$ and $\mathrm{Mo}$ on transformation products using advanced EBSD analysis. In: Proceedings HSLA Steels 2015, Microalloying 2015 \& Offshore Engineering Steels (2015) 143-149. doi:10.1007/978-3-319-48767-0_12

[10] C. Garcia-Mateo, F. G. Caballero, T. Sourmail, J. Cornide, V. Smanio, R. Elvira, Composition design of nanocrystalline bainitic steels by diffusionless solid reaction, Met. Mater. Int. 20 (2014) 405-415. doi:10.1007/s12540-014-3002-9

[11] M. X. Zhou, G. Xu, H. J. Hu, Q. Yuan, J. Y. Tian, Kinetics model of bainitic transformation with stress, Met. Mater. Int. 24 (2018) 28-34. doi:10.1007/s12540-017-7261-0

[12] N. V. Luzginova, L. Zhao, J. Sietsma, Bainite formation kinetics in high carbon alloyed steel, Mat. Sci. Eng. A 481-482 (2008) 766-769. doi:10.1016/j.msea.2006.11.173

[13] M. X. Zhou, G. Xu, L. Wang, H. J. Hu, Combined effect of the prior deformation and applied stress on the bainite transformation, Met. Mater. Int. 22 (2016) 956-961. doi:10.1007/s12540-016-6293-1

[14] G. H. Chen, G. Xu, H. J. Hu, Q. Yuan, Q. X. Zhang, Effect of strain rate on deformation resistance during ausforming in Fe-C-Mn-Si high-strength bainite steels, Steel. Res. Int. 89 (2018) 1800201. doi:10.1002/srin.201800201

[15] W. Gong, Y. Tomota, M. S. Koo, Y. Adachi, Effect of ausforming on nanobainite steel, Scr. Mater. 63 (2010) 819-822. doi:10.1016/j.scriptamat.2010.06.024
[16] W. Gong, Y. Tomota, Y. Adachi, A. M. Paradowska, J. F. Kelleher, S. Y. Zhang, Effects of ausforming temperature on bainite transformation, microstructure and variant selection in nanobainite steel, Acta Mater. 61 (2013) 4142-4154. doi:10.1016/j.actamat.2013.03.041

[17] R. H. Larn, J. R. Yang, The effect of compressive deformation of austenite on the Widmanstätten ferrite transformation in Fe-Mn-Si-C steel, Mat. Sci. Eng. A 264 (1999) 139-150. doi:10.1016/s0921-5093(98)01085-5

[18] H. J. Hu, H. S. Zurob, G. Xu, D. Embury, G. R. Purdy, New insights to the effects of ausforming on the bainitic transformation, Mat. Sci. Eng. A 626 (2015) 34-40. doi:10.1016/i.msea.2014.12.043

[19] J. He, A. Zhao, C. Zhi, H. L. Fan, Acceleration of nanobainite transformation by multi-step ausforming process, Scr. Mater. 107 (2015) 71-74. doi:10.1016/i.scriptamat.2015.05.023

[20] C. Garcia-Mateo, F. G. Caballero, T. Sourmail, M. Kuntz, J. Cornide, V. Smanio, R. Elvira, Tensile behaviour of a nanocrystalline bainitic steel containing 3 wt.\% silicon, Mat. Sci. Eng. A 549 (2012) 185-192. doi:10.1016/i.msea.2012.04.031

[21] H. J. Hu, G. Xu, L. Wang, M. X. Zhou, Z. L. Xue, Effect of ausforming on the stability of retained austenite in a C-Mn-Si bainitic steel, Met. Mater. Int. 21 (2015) 929-935. doi:10.1007/s12540-015-5156-5

[22] R. Freiwillig, J. Kudrman, P. Chráska, Bainite transformation in deformed austenite, Metall. Mater. Trans. A 7 (1976) 1091-1097. doi:10.1007/bf02656591

[23] G. H. Chen, G. Xu, H. S. Zurob, H. J. Hu, X. L.Wan, Effect of strain rate on the bainitic transformation in Fe-C-Mn-Si medium-carbon bainitic steels, Metall. Mater. Trans. A 50 (2019) 573. doi:10.1007/s11661-018-5051-Z

[24] R. H. Edwards, N. F. Kennon, The morphology and mechanical properties of bainite formed from deformed austenite, Metall. Mater. Trans. A 9 (1978) 1801-1809. doi:10.1007/bf02663411

[25] C. S. Chiou, J. R. Yang, C. Y. Huang, The effect of prior compressive deformation of austenite on toughness property in an ultra-low carbon bainitic steel, Mater. Chem. Phys. 69 (2001) 113-124. doi:10.1016/s0254-0584(00)00379-5

[26] M. Liu, G. Xu, J. Y. Tian, Q. Yuan, M. X. Zhou, H. J. Hu, The effect of stress on bainite transformation, microstructure, and properties of a low-carbon bainitic steel, Steel Res. Int. 90 (2019) 1900159. doi:10.1002/srin.201900159 